\title{
Colonization factors of Campylobacter jejuni in the chicken gut
}

\author{
David Hermans ${ }^{1 *}$, Kim Van Deun ${ }^{1}$, An Martel ${ }^{1}$, Filip Van Immerseel ${ }^{1}$, Winy Messens ${ }^{2,3}$, Marc Heyndrickx ${ }^{1,2}$, \\ Freddy Haesebrouck ${ }^{1}$ and Frank Pasmans ${ }^{1}$
}

\begin{abstract}
Campylobacter contaminated broiler chicken meat is an important source of foodborne gastroenteritis and poses a serious health burden in industrialized countries. Broiler chickens are commonly regarded as a natural host for this zoonotic pathogen and infected birds carry a very high C. jejuni load in their gastrointestinal tract, especially the ceca. This eventually results in contaminated carcasses during processing. Current intervention methods fail to reduce the colonization of broiler chicks by $C$. jejuni due to an incomplete understanding on the interaction between C. jejuni and its avian host. Clearly, C. jejuni developed several survival and colonization mechanisms which are responsible for its highly adapted nature to the chicken host. But how these mechanisms interact with one another, leading to persistent, high-level cecal colonization remains largely obscure. A plethora of mutagenesis studies in the past few years resulted in the identification of several of the genes and proteins of $C$. jejuni involved in different aspects of the cellular response of this bacterium in the chicken gut. In this review, a thorough, up-todate overview will be given of the survival mechanisms and colonization factors of $C$. jejuni identified to date. These factors may contribute to our understanding on how C. jejuni survival and colonization in chicks is mediated, as well as provide potential targets for effective subunit vaccine development.
\end{abstract}

\section{Table of contents}

1. Introduction

2. C. jejuni colonization pattern in broiler chicks

3. C. jejuni colonization factors in the chicken gut

3.1. Multidrug and bile resistance

3.2. Chemotaxis

3.3. Flagella and motility

3.4. Surface-accessible carbohydrate structures and immune evasion

3.5. Two-component regulatory systems

3.6. Temperature regulation and heat shock response

3.7. Adhesion

3.8. Invasion

3.9. Iron transport and regulation

3.10. Oxidative and nitrosative stress defence

3.11. Central intermediary and energy metabolism

* Correspondence: david.hermans@ugent.be

'Department of Pathology, Bacteriology and Avian Diseases, Faculty of Veterinary Medicine, Ghent University, Salisburylaan 133, 9820 Merelbeke, Belgium

Full list of author information is available at the end of the article
4. Vaccine application versus immune evasion

5. Concluding remarks

Acknowledgements

Author details

Authors' contributions

Authors' information

Competing interests

References

\section{Introduction}

Campylobacter infections are now the leading cause of human bacterial gastroenteritis in many developed countries [1,2]. Campylobacter enteritis in humans is mainly caused by C. jejuni [2]. Chickens are a natural host for Campylobacter species and are often colonized by C. jejuni in particular [2]. Therefore, this review will focus on the interaction of $C$. jejuni with the broiler chick in particular. Transmission to humans probably most commonly occurs through consumption and handling of chicken meat products contaminated with this zoonotic pathogen during slaughter and carcass processing $[3,4]$, in which Campylobacter colonization of the chicken intestinal tract plays an important role [5]. The

\section{Biomed Central}


chicken reservoir as a whole is estimated to be responsible for up to $80 \%$ of human campylobacteriosis cases [4]. But despite many efforts, current intervention methods fail to reduce the colonization of chickens with Campylobacter [6]. Intensive research in the past few years resulted in an increased insight into the colonization mechanism of $C$. jejuni in chicks, with several of its colonization factors identified. This newly gathered information, which is the topic of this review, might aid in the development of new effective vaccines to reduce $C$. jejuni prevalence in broiler flocks and eventually the number of chicken meat-related human campylobacteriosis cases.

\section{C. Jejuni Colonization Pattern in Broiler Chicks}

It is generally accepted that $C$. jejuni colonizes the avian gut as a commensal and colonized broilers carry a large number of bacteria in their ceca (generally around $10^{6}$ to $\left.10^{8} \mathrm{cfu} / \mathrm{g}\right)$, the predominant site for colonization $[7,8]$. Ingestion of $C$. jejuni numbers as few as 35 cfu can be sufficient for successful colonization of chicks [9]. After ingestion, the bacterium reaches the cecum and multiplies, resulting in an established colonizing Campylobacter population within 24 hours after entrance [10]. Most flocks become colonized only at an age of two to four weeks $[11,12]$, probably due to the presence of maternallyderived antibodies in young chicks conferring protection against colonization [13]. Once flock colonization is detected, the majority (> 95\%) of the birds of that flock is colonized within several days [14] and stay so until slaughter $[10,15]$.

C. jejuni isolates can have different colonization potential $[9,16,17]$. Isolates from humans have been reported to be less successful in colonizing chickens than poultry isolates $[17,18]$. C. jejuni isolates from poultry have been divided in three colonization phenotypes. Strains of the first phenotype fail to colonize 14-day-old chickens. In the second phenotype, strains can colonize but are readily eliminated and are classified as transient. The third phenotype contains strains that show efficient and sustained colonization $[16,18]$. These three colonization phenotypes were found to be stable and independent of in vivo passages and the amount of viable bacteria in the inoculum. Although C. jejuni strains did show enhanced colonization capacity (i.e. the minimal infective dose required for maximal colonization decreased) after passage through the avian gastrointestinal (GI) tract, their colonization phenotype did not change [17]. Enhanced colonization capacity and increased virulence after in vivo passage through chicks has been shown in several other studies as well $[9,19,20]$. This variability in colonization capacity, but the fixedness of the colonization phenotype of a given strain indicates that $C$. jejuni genes involved in initial and sustained colonization are not identical. However, in contrast to this stable colonization phenotype [17], it has been previously reported that after several in vivo passages a poorly colonizing isolate was able to consistently colonize chicks [9].

\section{C. Jejuni Colonization Factors in the Chicken Gut}

As in the environment, also in the chicken intestine C. jejuni is likely to encounter environmental stressors compromising optimal growth [21]. The persistent colonization of the chicken GI tract by $C$. jejuni indicates that the bacterium harbours regulatory systems that confer protection toward a hostile environment inside, but also outside the host. The mechanism by which the bacterium adapts to this "hostile" environment, resulting in successful and persistent colonization, is poorly understood. It is clear, however, that successful colonization of the chicken GI tract is a multifactorial process [22] in which genes involved in all areas of the colonization process of $C$. jejuni play a role. In the next sections, a thorough, up-to-date overview is given on identified colonization factors of $C$. jejuni in the chicken gut, summarized in Table 1.

\subsection{Multidrug and bile resistance}

The Campylobacter multidrug efflux pump (CME) plays an important role in multidrug resistance in C. jejuni, mediating resistance to heavy metals and a broad range of antibiotics and other antimicrobial agents [23]. It is also responsible for resistance to bile salts in the chicken intestinal tract and is therefore essential for successful intestinal colonization in chickens [24]. CME is encoded by the operon cme $A B C$ and consists of a periplasmic protein (CmeA), an inner membrane efflux transporter $(\mathrm{CmeB})$ and an outer membrane protein $(\mathrm{CmeC})$. Expression of cmeABC in C. jejuni is modulated by $\mathrm{CmeR}$, functioning as a transcriptional repressor [23]. In a $c m e R$ mutant, one gene in particular was upregulated most compared to the wild type strain: cj0561c, encoding a putative periplasmic protein [25]. It is suggested that CmeR directly inhibits the transcription of this gene. The expression of both $c m e A B C$ and $c j 0561 c$ is strongly induced by bile compounds present in the chicken intestinal tract and expression of $\mathrm{Cj0561c}$ is increased over four-fold during chicken colonization $[25,26]$. Inactivation of cj0561c and loss-of-function mutation of CmeR resulted in reduced fitness of C. jejuni in chickens and impaired ability to colonize chicks, respectively [25]. Finally, a mutant in the Campylobacter bile resistance regulator $(c b r R)$ gene, coding for the response regulator $\mathrm{CbrR}$, was shown to be sensitive to bile components in vitro [27]. In addition, this mutant had reduced colonization ability in chicks indicating that also in vivo CbrR modulates resistance to bile salts in C. jejuni. Together these observations 
Table 1 To date identified colonization factors of Campylobacter jejuni in the avian gastrointestinal tract

\begin{tabular}{|c|c|c|c|}
\hline Functional area & $\begin{array}{l}\text { Gene name or } \\
\text { locus }\end{array}$ & Identified/predicted protein function & Reference \\
\hline Multidrug efflux pump & $\begin{array}{l}\text { cmeABC } \\
\text { cmeR } \\
\text { cj0561c } \\
\text { cbrr }^{*}\end{array}$ & $\begin{array}{l}\text { Campylobacter multidrug efflux pump } \\
\text { transcriptional repressor of } \mathrm{cmeABC} \\
\text { putative periplasmic protein } \\
\text { Campylobacter bile resistance orphan response regulator }\end{array}$ & $\begin{array}{l}{[2} \\
{[2}\end{array}$ \\
\hline Chemotaxis & $\begin{array}{l}\frac{d o c B}{d o c C} \\
\frac{\text { acfB }}{\text { cheY }} \\
\frac{\text { tIp1 }}{\text { luXS }} \\
\text { cheB, cher }\end{array}$ & $\begin{array}{l}\text { probable methyl-accepting chemotaxis protein (MCP) } \\
\text { probable MCP protein } \\
\text { probable MCP protein } \\
\text { chemotaxis regulatory protein } \\
\text { chemoreceptor transducer-like protein } \\
\text { signal autoinducer Al-2 biosynthesis enzyme } \\
\text { putative adaptation proteins }\end{array}$ & $\begin{array}{l}{[26]} \\
{[32]} \\
{[33]} \\
{[35]} \\
{[29]}\end{array}$ \\
\hline Motility & $\begin{array}{l}\text { flaA } \\
\text { maf5 } \\
r p o N \\
\text { fliA } \\
\frac{f l g R}{f l g K} \\
\text { cj1321- } j 1325 / 6\end{array}$ & $\begin{array}{l}\text { major flagellin } \\
\text { motility accessory factor (flagellar biosynthesis) } \\
\text { RNA polymerase } \sigma^{54} \text { subunit } \\
\text { RNA polymerase } \sigma^{28} \text { subunit } \\
\text { response regulator } \\
\text { possible flagellar hook associated protein } \\
\text { flagellin O-linked glycosylation island }\end{array}$ & $\begin{array}{r}{[44,45]} \\
{[44]} \\
{[32,48]} \\
{[32,43]} \\
{[32,48]} \\
{[52]}\end{array}$ \\
\hline $\begin{array}{l}\text { Capsule formation and } \mathrm{N} \text {-linked } \\
\text { glycosylation }\end{array}$ & $\begin{array}{l}\text { kpsM } \\
\text { pglH } \\
\text { cj1496c }\end{array}$ & $\begin{array}{l}\text { high molecular weight glycan } \\
\text { probable glycosyltransferase } \\
\text { glycoprotein with unknown function }\end{array}$ & $\begin{array}{r}{[44]} \\
{[32,44,68]} \\
{[66]}\end{array}$ \\
\hline Two-component regulatory systems & $\begin{array}{l}\frac{r a c R}{d c c R}-\operatorname{rac} S \\
\quad c b r R \\
c p r R-c p r S \\
\text { flgR }- \text { flgs }\end{array}$ & $\begin{array}{l}\text { reduced ability to colonize regulatory system } \\
\text { diminished capacity to colonize regulatory system } \\
\text { Campylobacter bile resistance orphan response regulator } \\
\text { Campylobacter planktonic growth regulation regulatory system } \\
\text { flagellar signal transduction system }\end{array}$ & $\begin{array}{r}{[71]} \\
{[72]} \\
{[27]} \\
{[73]} \\
{[32,43]}\end{array}$ \\
\hline $\begin{array}{l}\text { Temperature regulation and heat shock } \\
\text { response }\end{array}$ & $\begin{array}{l}\text { dnal } \\
\text { rack }\end{array}$ & $\begin{array}{l}\text { heat-shock protein } \\
\text { reduced ability to colonize response regulator }\end{array}$ & $\begin{array}{r}{[55,75]} \\
{[71]}\end{array}$ \\
\hline Adhesion & $\begin{array}{l}\text { capA? } \\
\text { cadF } \\
\text { pldA } \\
\text { peb1A } \\
\text { flpA }\end{array}$ & $\begin{array}{l}\text { autotransporter lipoprotein } \\
\text { outer membrane fibronectin-binding protein } \\
\text { outer membrane phospholipase A } \\
\text { periplasmic ABC transporter of amino acids } \\
\text { fibronectin-like protein A }\end{array}$ & $\begin{array}{r}{[76] \text { vs }} \\
[77]] \\
{[55,80]} \\
{[55,82]} \\
{[77,116]}\end{array}$ \\
\hline Invasion & $\begin{array}{l}\text { ciab } \\
\text { docB } \\
\text { docC } \\
\text { tipl }\end{array}$ & $\begin{array}{l}\text { Campylobacter invasion antigen B } \\
\text { probable MCP protein } \\
\text { probable MCP protein } \\
\text { chemoreceptor transducer-like protein }\end{array}$ & $\begin{array}{r}{[55]} \\
{[31,32]} \\
{[31,33]}\end{array}$ \\
\hline Iron regulation & $\begin{array}{l}\text { feoB } \\
\text { fur } \\
\text { cfrA } \\
\text { ceuE } \\
\text { cfrB } \\
\text { chuA } \\
\text { cjol78 } \\
\text { znuA }\end{array}$ & $\begin{array}{l}\text { specific transporter protein } \\
\text { ferric uptake regulator } \\
\text { (recessive) ferric enterobactin (FeEnt) receptor } \\
\text { FeEnt-uptake periplasmic binding protein } \\
\text { (dominant) FeEnt receptor } \\
\text { hemin uptake outer membrane protein } \\
\text { putative transferrin-bound iron utilization outer membrane } \\
\text { receptor } \\
\text { periplasmic component of a putative zinc ABC transport } \\
\text { system }\end{array}$ & $\begin{array}{l}{[90]} \\
{[26]} \\
{[88]} \\
{[91]}\end{array}$ \\
\hline $\begin{array}{l}\text { Oxidative and nitrosative stress } \\
\text { response }\end{array}$ & $\begin{array}{l}\text { docA } \\
\text { cj0358 } \\
\text { sodB } \\
\text { perR } \\
\text { ahpC } \\
\text { katA } \\
\frac{\text { ggt }}{\text { ppk1 }} \\
\text { ppk2 } \\
\text { tatC } \\
\text { cjo379C }\end{array}$ & $\begin{array}{l}\text { putative cytochrome } c \text { peroxidase } \\
\text { putative cytochrome } c \text { peroxidase } \\
\text { superoxide dismutase } \\
\text { peroxide-sensing regulon } \\
\text { alkyl-hydroxyperoxidase peroxide stress regulon } \\
\text { catalase } \\
\gamma \text {-glutamyl transpeptidase } \\
\text { polyphosphate kinase } 1 \\
\text { polyphosphate kinase } 2 \\
\text { twin-arginine translocase (TAT) secretion system } \\
\text { TAT translocated molybdo-enzyme }\end{array}$ & $\begin{array}{r}{[32,94]} \\
{[26]} \\
{[95]}\end{array}$ \\
\hline
\end{tabular}




\begin{tabular}{|c|c|c|c|}
\hline Central intermediary and energy metabolism & $\begin{array}{c}\text { frdABC operon } \\
\text { aspA } \\
\text { hydABCD operon } \\
\text { fdhABCD operon } \\
\text { oorDABC } \\
\text { (12) nuo genes } \\
\text { nrfA } \\
\text { napAGHBLD operon } \\
\text { ccoNOQP operon } \\
\text { sdaA } \\
\text { cj0415 } \\
\text { livJ } \\
\text { cj0903C } \\
\text { peb1A } \\
\text { ggt }\end{array}$ & $\begin{array}{l}\text { fumarate reductase } \\
\text { aspartate ammonia-lyase } \\
\text { hydrogenase } \\
\text { formate dehydrogenase } \\
\text { 2-oxoglutarate:acceptor oxidoreductase } \\
\text { NADH:ubiquinone oxidoreductase (complex I) } \\
\text { nitrite reductase } \\
\text { nitrate reductase } \\
\text { cbb-type cytochrome c oxidoreductase } \\
\text { L-serine dehydratase } \\
\text { putative oxidoreductase subunit } \\
\text { putative amino acid ABC transporter periplasmic-binding } \\
\text { protein } \\
\text { putative amino acid transport protein } \\
\text { periplasmic ABC transporter of amino acids } \\
\gamma \text {-glutamyl transpeptidase }\end{array}$ & $\begin{array}{r}{[109]} \\
{[26,115]} \\
{[110]} \\
\\
\\
{[111]} \\
\\
\\
{[26,114]} \\
{[112]} \\
{[32]} \\
{[77,110,116]} \\
{[99,100]}\end{array}$ \\
\hline
\end{tabular}

* Underlined and bold: genes having (probable) multiple functions

indicate that bile salts and multidrug resistance is crucial for $C$. jejuni to survive in the chicken gut.

\subsection{Chemotaxis}

Since $C$. jejuni is a highly motile bacterium, chemotaxis might be an important factor promoting its migration toward favourable conditions, and thus its survival in and colonization of the intestinal mucosa. For successful chemotaxis, an intact gradient-sensing mechanism, in which adaptation has a crucial role, is indispensable. The C. jejuni genome contains genes encoding putative adaptation proteins: a methylesterase CheB and a methyltransferase CheR, which are both involved in a methylationdependent chemotaxis pathway [28]. A $\Delta$ cheBR mutant was shown to have a reduced ability to colonize the chick cecum [29]. C. jejuni is attracted by the glycoprotein mucin, the principal constituent of mucus, and also by the bile and mucin constituent L-fucose. The amino acids aspartate, cysteine, serine and glutamate, and the salts of the organic acids citrate, fumarate, $\alpha$-ketoglutarate, malate, pyruvate and succinate also act as chemoattractants [30]. Additionally, L-asparagine, formate and D-lactate were recently identified as attractants of $C$. jejuni [31]. Surprisingly, in this study, C. jejuni was not attracted to citrate and L-fucose. All these chemicals are sensed by the transmembrane methyl-accepting chemotaxis proteins (MCP) of C. jejuni [31]. Hendrixson \& DiRita [32] identified 22 C. jejuni genes involved in colonization of the chicken GI tract. Severely affected colonization capacity particularly resulted from mutation in the determinant of chick colonization gene $\mathrm{B}(\operatorname{doc} B)$, encoding a putative $\mathrm{MCP}$ and alternatively called chemoreceptor transducer-like protein 10 (Tlp10). DocC (Tlp4), another MCP, was important for obtaining wild type colonization levels. Finally, also Tlp1 is important for chick colonization since a $t l p 1$-isogenic mutant showed reduced colonization ability $[32,33]$. Surprisingly, all three chemoreceptors (tlp1, tlp4 and tlp10) have been identified as being important for invasion (see further) of $C$. jejuni in chicken embryo intestinal cells (used as a model for in vivo invasion in chicken gut epithelial cells), but not for chemotaxis [31]. While it is clear that these factors contribute to in vivo colonization, their precise role in colonization requires further study. The putative accessory colonization factor $(a c f B)$, encoding a probable MCP protein, is highly upregulated in the chick cecum and although not important in the early stages of colonization, it cannot be ruled out that it might be involved in the persistence of $C$. jejuni in the chick cecum in the presence of a developed gut flora [26]. A number of other genes as well have been associated with $C$. jejuni chemotaxis, including the Campylobacter energy taxis response genes $\operatorname{cet} A$ and $\operatorname{cet} B$ [34] and the chemotaxis regulatory gene $c h e Y$, which codes for a response regulator controlling flagellar rotation and is involved in the same signal transduction pathway as CheBR [28]. A cheY mutant was affected in its colonization potential of the chick cecum [32]. Also the production of the signal autoinducer AI-2 has been shown to be important for colonization [35]. Inactivation of $l u x S$, the gene encoding the AI-2 biosynthesis enzyme, lead to a decrease in chemotaxis toward organic acids, in vitro adherence to chicken hepatoma (LMH) cells and chick colonization. These observations indicate that energy taxis may be an important force in environmental navigation by $C$. jejuni, driving the organism toward optimal chemical conditions for colonization.

\subsection{Flagella and motility}

Intact and motile flagella are important colonization factors for C. jejuni in chickens [36]. C. jejuni contains one or two polar flagella. The flagellar filament consists of multimers of the protein flagellin and is attached by the hook protein to a basal structure, embedded in the cell membrane and serving as a motor for rotation. The flagellin locus contains two adjacent genes, fla $\mathrm{A}$ 
(encoding the major flagellin) and flaB (encoding a minor flagellin). Both genes are independently transcribed, with the flaA gene regulated by a $\sigma^{28}$ promoter and the flaB gene by a $\sigma^{54}$ promoter $[32,37,38]$. Environmental and chemotactic stimuli modulate fla $A$ and flaB promoter activity. Medium $\mathrm{pH}$, growth temperature and the concentration of certain inorganic nutrients affect $f l a B$ promoter activity [39]. Lower $\mathrm{pH}$, bovine bile, deoxycholate, L-fucose, high osmolarity and chemotactic effectors such as aspartate, glutamate, citrate, fumarate, $\alpha$-ketoglutarate and succinate all upregulate the flaA promoter. Proline, high viscosity and milk fermented by Bifidobacterium or Lactobacillus strains downregulate the flaA promoter [40,41]. The flaA gene seems to be highly conserved among Campylobacter isolates and transcription is usually higher than that of flaB [42]. Transcription of $\sigma^{54}$-dependent genes, necessary for assembly of the hook-basal body filament structure, is regulated by a two-component system composed of the sensor kinase FlgS and the response regulator FlgR [43]. Experiments with mutants have shown that flaA but not flaB is essential for colonization of chickens $[44,45]$ although probably both are needed for full motility [46]. Colonization is also impaired with the mutant for the motility accessory factor 5 (maf5) gene, important for the formation of flagella $[44,47]$. Once $C$. jejuni reaches the cecum, it seems that mutants in the flagellar biosynthesis genes rpoN (encoding $\sigma^{54}$ ) and fliA (encoding $\sigma^{28}$ ) and the response regulator gene flgR could establish colonization at a high inoculation dose, albeit bacterial numbers were much lower compared to the controls and the number of chicks colonized by these mutants was extremely low $[32,43,48]$. Chickens exposed to the $f l g R$ mutants showed a delayed colonization. Moreover, a re-infection of Campylobacter-negative chickens was not observed. Since bird-to-bird transmission in flocks is generally considered to be very rapid, this indicates that the FlgS/FlgR system is mainly required for initial colonization and less for survival and persistence in the cecum of chicks [43]. Also the flgK mutant, expressing only the hook, showed diminished motility and was completely attenuated for colonizing the chick cecum [48]. Further supporting indications that flagella are important colonization factors for $C$. jejuni in chickens was given by Hiett et al. [49]. These authors demonstrated differential expression patterns of flagella proteins between a poor and a robust colonizer strain in poultry. These differentially expressed genes, coding for proteins involved in the modification of the flagellum, are located in hypervariable regions of the $C$. jejuni genome. This variability was shown to be extendable to the protein level, and thus may contribute to the survival of C. jejuni in its different environments and hosts.
In $C$. jejuni chicken isolates, the flagellin O-linked glycosylation island, responsible for successful flagellin assembly and motility, is very diverse [50]. Five genes (cj1321 cj1325/6) lying in this variable region are, however, significantly prevalent among $C$. jejuni strains associated with poultry [51] and might therefore be important for the ability of certain C. jejuni strains to colonize this host. Mutagenesis and functional and structural data supported this hypothesis, with particularly cj1324 being important for chick colonization [52].

The flagellar apparatus functions as a type III secretion apparatus for the Campylobacter invasion antigens (Cia proteins) [53], important for in vitro cell invasion [54] and chick colonization [55], and secretion is enhanced upon exposure to chicken mucus [56]. A correlation has been demonstrated between chicken colonization potential and in vitro secretion of Cia proteins [56]. RpoN mutants are completely aflagellated and as such do not secrete Cia proteins, nor do flgK mutants [48], making it clear that the molecular basis behind the colonization mechanism in chickens is complex.

The role of motility of $C$. jejuni colonization in the chicken GI tract is not fully understood. Non-motile C. jejuni mutants can colonize chickens, be it at substantially reduced levels and only when chickens are inoculated with high amounts of viable cells [43]. Probably, motility is needed for C. jejuni to pass the GI tract so it can reach its protective niche, the mucus layer of the cecal crypts [7], and to resist gut peristalsis [32], hence it is important for initial colonization. It is, however, not known if motility is important in the persistence of C. jejuni in the intestinal tract, leading to long-term colonization. In any case it is clear that the specialized flagellum of $C$. jejuni serves multiple functions in the adaptation of $C$. jejuni to the chicken GI tract.

\subsection{Surface-accessible carbohydrate structures and immune evasion}

Several surface-accessible carbohydrate structures (SACS) such as flagella, lipooligosaccharides (LOS), a capsule and $O$ - and $N$-linked glycans contribute to $C$. jejuni colonization in chicks.

In C. jejuni, the lipopolysaccharide molecule only consists of lipid A and the (inner and outer) core oligosaccharide and is therefore referred to as LOS, as the high-molecularweight $O$-polysaccharide is a capsular polysaccharide not linked to the lipopolysaccharide molecule [57]. C. jejuni LOS is important for immune evasion in humans as well as host cell adhesion and invasion, and sialylation of the LOS outer core further enhances epithelial cell invasion [58]. Moreover, sialylated LOS results in reduced immunogenicity [59] and increased invasion potential in Caco-2 cells [60]. The majority of strains from human and chicken origin belonging to the clonal complex CC-21, an ecologically 
diverse and the largest complex in the general population structure of $C$. jejuni, were found to belong to one sialylated LOS class in particular, LOS class $C$, correlating with a high invasive potential [60]. Thus, sialylation of the LOS outer core is likely to contribute to successful colonization of C. jejuni in a suitable host. Genes responsible for the formation of the polysaccharide capsule, surrounding the surface of C. jejuni cells and possibly involved in survival, adherence and evasion of the host's immune system [57,61], also play a role in colonization of the chicken intestine by C. jejuni. Mutation in the capsular polysaccharide transporter gene $\mathrm{M}(k p s M)$, which results in the loss of a high molecular weight glycan, and thus absence of a capsule, abolished colonization of chickens [44,62]. A C. jejuni mutant for the $k p s E$ gene, which is unable to express any capsular polysaccharide, was not hampered in its ability to colonize the chicken intestinal tract but the number of bacteria recovered from cecum and colon were lower compared to the control [63]. Interpretation of these results is hampered by the use of different chicken in vivo models and bacterial strains. Capsule formation and LOS biosynthesis genes are located in hypervariable regions in the C. jejuni genome [64], resulting in an enormous antigenic diversity among isolates.

C. jejuni is unique in being the only known prokaryote having an $N$-linked protein modification system, which is encoded by the $p g l$ multigene locus $[65,66]$. The $N$-linked glycosylation pathway is responsible for post-translational modification of multiple proteins, including flagellin, and is conserved among C. jejuni isolates [50,67]. In contrast, the only known proteins to be modified by $O$-linked glycosylation in $C$. jejuni (see above) are flagellar subunits [50]. In humans, most of the $N$-linked glycosylated proteins are highly immunogenic with their glycosyl moieties being immunodominant while only limited antibody is generated against the protein fraction [67]. This indicates that glycosylation might offer C. jejuni a unique system of immune evasion by masking primary amino acid sequences. A mutant in the $N$-linked general protein glycosylation pathway gene $\mathrm{H}(\mathrm{pglH})$ possessed an intact capsule, but was unable to glycosylate proteins and was severely reduced in its ability to colonize the chicken intestinal tract $[44,68]$. Also strains with other mutations in the $p g l$ locus were affected in their ability to colonize chicks [32], indicating that $N$-linked glycosylation in C. jejuni is an important colonization determinant. However, glycan modification of Cj1496c, a glycoprotein important for in vitro cell invasion in human epithelial cells and initial chick colonization does not seem to influence its function [66]. Moreover, most $N$-glycosylated proteins, including Cj1496c, are annotated to be periplasmatic and do not come in direct contact with host factors and the exact mechanism by which this glycosylation system contributes to colonization remains to be elucidated $[66,69]$.

To conclude, several SACS of $C$. jejuni, including the unique $N$-linked glycans, contribute to successful colonization in chicks. Not only by mediating adhesion (see further), but also by creating an enormous antigenic diversity in $C$. jejuni isolates resulting in persistent highlevel gut colonization of certain strains.

\subsection{Two-component regulatory systems}

C. jejuni, like all prokaryotes, responds to environmental changes by using two-component regulatory systems (TCRSs) consisting of response (R) regulators and sensor (S) kinases regulating C. jejuni gene expression [26,70]. A histidine kinase senses specific environmental triggers through autophosphorylation of the histidine residue. Subsequent transfer of the phosphate group to the corresponding response regulator turns it into an active transcription factor that can stimulate the differential expression of target genes, allowing $C$. jejuni to immediately respond to changing environmental conditions within the chicken gut such as several stressors, nutrients and temperature [70].

To date, five TCRSs have been identified in C. jejuni to be important for optimal chick colonization: FlgRS [43] and the orphan response regulator CbrR [28] (see above), the reduced ability to colonize (RacRS) system [71], diminished capacity to colonize (DccRS) [72] and Campylobacter planktonic growth regulation (CprRS) [73]. RacRS is responsive to temperature, and mutation of $r a c R$ reduces the colonization potential of $C$. jejuni $[26,71]$ (see also below). DccRS controls the expression of several genes encoding probable membrane-associated proteins [26]. Finally, CprRS is thought to control essential biological processes, stress tolerance and biofilm formation, making it possible for $C$. jejuni to adapt to different environments [73]. A $\Delta c p r S$ mutant was reported to display a dramatic dose-dependent defect for chick colonization. Thus, it is clear that the genome of $C$. jejuni harbours multiple TCRS genes, involved in all aspects of $C$. jejuni biology, which are vital for its efficient adaptation to the chicken host.

\subsection{Temperature regulation and heat shock response}

The elevated body temperature of the chicken $\left(42^{\circ} \mathrm{C}\right)$ as compared to humans implies the transcription of many different proteins uniquely transcribed in response to the chicken GI tract. The RacR/RacS signal transduction system responds to temperature changes and might play an important role in chicken colonization by C. jejuni [71]. Comparative analysis of the protein profile of wild type C. jejuni and racR mutants, revealed 11 proteins to belong to the RacR regulon. Three proteins were sequenced and were identified as RacR and two isoforms of a cytochrome 
$c$ peroxidase homologue. A comparative study by Zhang et al. [74] revealed 15 to 20 proteins differentially expressed by at least two-fold when $C$. jejuni was grown at $37^{\circ} \mathrm{C}$ or at $42^{\circ} \mathrm{C}$. All identified differentially expressed proteins are periplasmic proteins or major antigens of $C$. jejuni, or are involved in the metabolism or regulatory system. These proteins might play a role in adaptation to and pathogenicity in the different hosts of C. jejuni. DnaJ belongs to a family of heat shock proteins and plays a role in C. jejuni thermotolerance [75]. The dnaJ gene is located adjacent to racR and likely to be under the transcriptional control of RacR [71]. Mutation of $d n a J$ severely reduced colonization in chicks $[55,75]$.

\subsection{Adhesion}

Campylobacter adhesion to epithelial cells of the chicken GI tract is believed to be an important step in successful colonization. Several studies contributed to the importance of intact flagella and adhesins, surface-exposed proteins, in chicken colonization. Mutation of the Campylobacter adhesion protein A (capA) gene, encoding an autotransporter lipoprotein, resulted in reduced capacity to adhere to human and chicken intestinal epithelial cells, reduced invasion capacity in human epithelial cells and abolished colonization in a chick model [76,77]. In another study, however, mutation of capA did not result in reduced colonization capacity [77]. Moreover, since this gene is absent in many $C$. jejuni poultry isolates, the genuine contribution of capA to successful chick colonization is unclear $[77,78]$. The Campylobacter adhesion to fibronectin (CadF) outer membrane protein was shown to bind to fibronectin, a glycoprotein of the extracellular matrix of the GI tract [79], and to be important for full binding capacity of $C$. jejuni to chicken epithelial cells [77]. Ziprin et al. $[55,80]$ demonstrated that mutants in the genes $c a d F$ and $p l d A$, the structural gene for phospholipase A, are impaired in their ability to colonize the cecum, indicating that these genes may play a prominent role in successful colonization. But in contrast to the highly prevalent $c a d F$ gene, many $C$. jejuni isolates lack the pldA gene [81]. Moreover, the biological function of pldA is not known. But due to its outer membrane localization it might be involved in maintaining the functional integrity of surface exposed adhesins in some strains [82]. Hiett et al. [49] demonstrated differential expression patterns for major outer membrane proteins in poultry between a poor and a robust colonizer strain. These differentially expressed genes are located in hypervariable regions of the $C$. jejuni genome and may contribute to the survival of $C$. jejuni in its different environments and hosts. Recently, a new adhesin, fibronectin-like protein A (FlpA), has been identified to be important for full binding capacity to chicken epithelial cells and successful colonization [77]. Konkel et al. [83] found that different C. jejuni strains compete for colonization in broilers and hypothesized that this is due to the sharing of common adhesins among these isolates and limited host epithelial cell binding places. This finding supports the hypothesis that adhesion is a key step in the colonization process of $C$. jejuni in chicks.

\subsection{Invasion}

Invasion might be an important colonization determinant of $C$. jejuni in chicks because mutations in $c i a B$ as well as in the MCP genes $t l p 1, t l p 4$ and $t l p 10$, important for in vitro invasion in mammalian and chicken cells respectively (see above), severely impair cecal colonization $[31,55]$. Studies with isolated primary intestinal cells from chickens indeed showed that $C$. jejuni was able to invade chicken cells $[84,85]$, an unexpected feature since C. jejuni does not associate with chicken crypt epithelium in vivo [85]. Invasion capacity was largely strain-dependent, but overall no difference was observed between isolates from poultry or human origin. Microtubule- as well as microfilament-dependent invasion was reported, which is in accordance with results obtained from invasion experiments in human epithelial cell lines [86]. Many studies on the genes which are thought to play a role during invasion have been conducted on human epithelial cell lines, but thus far experiments on chicken primary epithelial cecal cells are lacking. While it is tempting to assume that invasion mechanisms in these cells are analogous to those in human cell lines, some differences do exist: $C$. jejuni can survive in vitro in human T84 epithelial cells by avoiding fusion with lysosomes [87], but intracellular survival seems not to be the case in the primary chicken enterocytes [84]. The lack of an immortalized chicken intestinal cell line and the complicated handling of primary chicken cecal cells clearly hamper investigation toward invasion (and other) mechanisms in chicken cecal cells. Nevertheless, the recent obtained in vitro and in vivo results described under this section suggest that invasion of $C$. jejuni in gut epithelial cells might be an important colonization determinant in vivo.

\subsection{Iron transport and regulation}

Regulation of the intracellular iron concentration is an important factor to secure colonization. Iron is essential for electron transfer processes and functions as a cofactor for several enzymes. It is also responsible for the generation of hydroxyl radicals. Moreover, iron availability modulates the transcription of genes belonging to several functional groups, thereby affecting the ability of $C$. jejuni to colonize the GI tract [88]. The soluble ferrous iron $\left(\mathrm{Fe}^{2+}\right)$ is readily transported across the outer membrane via porins and is subsequently transported across the cytoplasmic membrane by a specific transporter protein, FeoB. This transporter is important for iron acquisition 
and intracellular survival of C. jejuni, as well as for successful gut colonization [89]. Mutants in the ferric uptake regulator (fur) gene, the $c f r A$ gene responsible for an outer membrane ferric enterobactin (FeEnt) receptor and the $c e u E$ gene encoding a FeEnt periplasmic binding protein regulated by fur, are all compromized in their ability to colonize chickens, with complete absence of live bacteria for the latter two [88], as were mutants in another recently identified and characterized outer membrane FeEnt receptor $\mathrm{CfrB}$, which is most prevalent in C. coli strains [90]. Inactivation of $c f r B$ in a $c f r A$-negative C. jejuni strain fully abolished its ability to utilize FeEnt as a sole iron source for growth. Moreover, the reduced colonization phenotype of the isogenic $c f r B$ mutant of $C$. jejuni could not be restored by the presence of a functional cfrA gene. In contrast, complementation of an isogenic $c f r A$ mutant with the wild type $c f r B$ gene in trans fully restored the ability of this $C$. jejuni mutant to utilize FeEnt. Thus, CfrB plays an important role during colonization of Campylobacter in chicks and cannot be compensated by other iron uptake mechanisms without affecting the colonization potential. Therefore, it is believed that $\mathrm{CfrB}$ is the dominant receptor both in FeEnt utilization by and during colonization of chickens with $C$. jejuni strains producing both a functional CfrA and CfrB. Transcription levels of $c h u A$, a gene believed to code for an outer membrane receptor for hemin and hemoglobin, are increased over 40 -fold in the chicken cecum, indicating that ChuA might be required for C. jejuni to colonize chicks [26]. Finally, mutation in Cj0178, a putative transferrin-bound iron utilization outer membrane receptor, resulted in reduced colonization potential [88]. Given this information, it can be concluded that several iron-uptake systems are essential for the survival of $C$. jejuni and for its successful colonization in the chicken host.

Besides iron, also zinc has been reported to be an important trace element necessary for $C$. jejuni growth inside the chicken host [91]. A C. jejuni mutant lacking ZnuA, the periplasmic component of a putative zinc ATP-binding cassette $(A B C)$ transport system, had a growth defect in zinc-limiting media and was severely affected in its colonization potential in chickens.

\subsection{Oxidative and nitrosative stress defence}

C. jejuni is a microaerophilic microorganism and thus requires reduced oxygen levels for its growth. Nevertheless, it must resist oxidative stress it may encounter both in the environment and in its host, like the superoxide anion, hydrogen peroxide and biotoxic hydroxyl radicals. These stressors can result from incomplete reduction of oxygen by $C$. jejuni, or be induced by the chick immune system [92]. C. jejuni contains a wide range of enzymes involved in defence against oxidative stress. Several of these regulators have already been identified. However, the mechanism of gene regulation in $C$. jejuni is still poorly understood. Cytochrome $c$ peroxidases $(\mathrm{CcPs})$ are generally responsible for the conversion of hydrogen peroxide to water [92]. In a study by Ahmed et al. [93] 23 DNA sequences, including cytochrome oxidase III, were found to be present in a robust but absent from a poor colonizer $C$. jejuni strain. No direct link could be found that these factors correlate with the identified genes by Hendrixson and DiRita [32], but it can be assumed that also these strain-specific genes are factors important for efficient and sustained colonization. C. jejuni has two CcP loci, which surprisingly do not contribute to hydrogen peroxide resistance and thus do not protect against oxidative stress. Instead, it seems that in C. jejuni resistance to hydrogen peroxide is mainly mediated by the sole cytoplasmic catalase KatA, breaking it down to water and oxygen [92,94]. Nevertheless, mutation in one of the two CcP loci, docA, located immediately upstream of $\operatorname{doc} B$, resulted in a substantial dose-dependant decrease in colonization potential $[32,94]$. Moreover, Woodall et al. [26] found Cj0358, another putative CcP, to be upregulated 12-fold in vivo suggesting a role for this protein in hydrogen peroxide removal from the periplasm. By constructing an isogenic $\Delta p e r R$ mutant, deficient in the regulon of the peroxide-sensing regulator (PerR), and comparing its transcriptome profile with that of the wild type strain, Palyada et al. [95] identified over 100 genes to be part of the PerR regulon. Mutation of perR significantly reduced $C$. jejuni motility and attenuated colonization in chickens. This study also revealed a functional network between the key players of the oxidative stress defence system, including mainly the antioxidant proteins encoded by the superoxide dismutase $(\operatorname{sodB})$, defending $C$. jejuni against the superoxide anion, the alkyl-hydroperoxide reductase $(a h p C)$ and $k a t A$, their transcriptional regulators fur and perR and the regulatory pathways that connect them. This indicates that there is a link between oxidative stress (PerR regulated) and iron metabolism (Fur regulated) in C. jejuni and that oxidative stress defence mechanisms and their proper regulation are essential for successful and efficient colonization of the chick cecum. Indeed, the colonization potential in chicks was reduced by 50000 -fold in the C. jejuni $\Delta a h p C$ mutant, while in $\Delta p e r R \Delta$ fur, $\Delta k a t A$ and $\Delta s o d B$ mutants colonization was completely abolished. This indicates that all key players of this functional network need to be intact for successful colonization of $C$. jejuni in chicks. Garenaux et al. [96] demonstrated that next to SodB, CadF and FlaA also a periplasmic protein $(\mathrm{Cj} 1371)$ and a two-component regulator (Cj0355c) were overexpressed following exposure to paraquat, a strong oxidizing agent. These findings suggest that both proteins play a role in C. jejuni oxidative stress resistance and might be 
important for persistent chick colonization, but this has yet to be demonstrated.

The enzyme $\gamma$-glutamyl transpeptidase (GGT) is involved in maintaining cellular glutathione levels. Glutathione is an antioxidant molecule providing vital cellular protection against reactive oxygen species, generated by aerobic respiration $[97,98]$. GGT was shown to be present in a robust but absent from a poor colonizer $C$. jejuni strain [93], suggesting that GGT activity is not needed for initial colonization but indispensable for persistence of $C$. jejuni in the avian gut [99]. GGT catalyzes the conversion of gluthatione and glutamine to glutamate, and the ability of certain $C$. jejuni strains to utilize glutamine or glutathione as a sole carbon source is absolutely dependent on the presence of GGT [100]. GGT is not present in all C. jejuni strains [99] which could explain the lower colonization capacity of strains lacking a functional GGT.

A $p p k 1$ and $p p k 2$ mutant, defective in respectively polyphosphate kinase 1 (PPK1) and 2 (PPK2), two key enzymes of the polyphosphate metabolization, were shown to have decreased invasion ability in human intestinal epithelial cells and a dose-dependent colonization defect in chicken ceca $[101,102]$. This indicates that the utilization and accumulation of polyphosphate helps $C$. jejuni to adapt to the cecal environment of the chick.

For survival and optimal colonization in the chick, $C$. jejuni must also be capable of eliciting a suitable response to cytotoxic nitric oxide (NO), a free radical produced by several cells of the host immune system that is bactericidal against C. jejuni [103]. C. jejuni is protected against NOinduced nitrosative stress by NO-detoxifying mechanisms, including a nitrite reductase and its single-domain Campylobacter globin (Cgb) [104,105]. Expression of Cgb in response to $\mathrm{NO}$ is not regulated by Fur nor PerR, but mediated by the transcription factor NssR, regulating a nitrosative stress-response regulon that also includes a truncated haemoglobin $(\mathrm{Ctb})$ probably involved in oxygen metabolism $[98,106]$. NO detoxification in C. jejuni is believed to proceed via a Cgb-catalyzed dioxygenase or denitrosylase reaction, converting $\mathrm{NO}$ and oxygen to nitrate [103].

Many C. jejuni redox proteins essential for electron transfer (see further) have $\mathrm{N}$-terminal twin-arginine translocase (TAT) signal sequences ensuring proper transport across the cytoplasmic membrane [107]. The TAT secretion system has been shown to be important for $C$. jejuni to cope with stress and for chick colonization [108]. A C. jejuni tatC knockout mutant had defects in biofilm formation, motility and flagellation, and was defective in survival under osmotic shock and oxidative and nutrient stresses, impairing the efficient transmission of $C$. jejuni to a susceptible host. The $\Delta t a t C$ mutant was unable to persistently colonize chickens which is likely the result of multiple, additive effects caused by the inability of the
tatC mutant to translocate essential TAT substrates [108]. Also a cj0379c mutant, lacking a functional TAT translocated molybdo-enzyme of unknown function, was deficient in chick colonization [107]. The nitrosative stress phenotype of this mutant suggests a role for Cj0379 in the reduction of reactive nitrogen species in the periplasm.

It is clear that within its chicken host $C$. jejuni can encounter several stressors which it must resist for successful colonization. The evidence above indicates that C. jejuni developed some interplaying survival mechanisms that allow the organism to cope with chicken gut-induced oxidative and nitrosative stress.

\subsection{Central intermediary and energy metabolism}

In $C$. jejuni, all enzymes necessary for a complete oxidative tricarboxylic acid cycle are present. A key step in this cycle is the oxidation of succinate to fumarate. Until recently, it was believed that in $C$. jejuni this reaction is exerted by both a fumarate reductase (Frd) and a succinate dehydrogenase ( $\mathrm{Sdh}$ ) since both enzymes were found to contribute to the total fumarate reductase of C. jejuni in vitro and were significantly upregulated in the chick cecum $[26,109]$. A C. jejuni mutant missing the intact FrdA subunit of the FrdABC enzyme was completely deficient in its succinate dehydrogenase activity in vitro and had reduced colonization ability in chicks. In contrast, experiments with the $s d h A$ mutant of $C$. jejuni showed that Sdh exhibits no succinate dehydrogenase activity and is not required for colonization, indicating that the $s d h$ operon has been misannotated. Thus, Frd is the sole succinate dehydrogenase of C. jejuni and is therefore essential for full host colonization [109].

To meet all of its energy demands, $C$. jejuni utilizes oxidative phosphorylation [110]. In the chicken cecum, however, C. jejuni encounters an environment with reduced oxygen levels to which it must elicit a suitable response to efficiently and persistently colonize this part of the gut. Microarray analysis revealed several genes involved in this response to be upregulated when $C$. jejuni enters its host compared to in vitro culture [26], with three genes in particular: the anaerobic $\mathrm{C}_{4}$-dicarboxylate transporter genes $d c u A$ and $d c u B$ as well as the aspartase gene asp $A$. Probably these genes play an important role during chick colonization. A double mutant in hydrogenase (Hyd) and formate dehydrogenase (Fdh) and a mutant in 2-oxoglutarate:acceptor oxidoreductase (OoR), had markedly reduced colonization ability in chicks, indicating the importance of these electron donor enzymes [110]. The same authors also identified NADH:ubiquinone oxidoreductase (complex I) to play an important role because a mutant in this gene showed impaired colonization capacitiy. Mutants in the respiratory enzymes nitrate reductase, nitrite reductase and $c b b_{3}$-type oxidase all colonize the chicken cecum to a lesser extent [111]. 
Moreover, these enzymes are upregulated in the chick cecum, indicating that $C$. jejuni might utilize nitrite and nitrate, as well as fumarate as a terminal electron acceptor instead of oxygen [26]. Especially nitrate is considered as a potential in vivo electron acceptor [104]. It is suggested that the ability of $C$. jejuni to use gluconate as an electron donor is important for full colonization potential in the avian host [112]. A cj0415 mutant, lacking gluconate dehydrogenase (GADH) activity, was impaired in establishing colonization in chicks but not in mice, which can probably explained by the higher expression level of cj0415 at $42^{\circ} \mathrm{C}$ compared to $37^{\circ} \mathrm{C}$ [112].

C. jejuni is an asaccharolytic bacterium and is therefore entirely dependent on a tight set of amino acids including L-aspartate, L-glutamate, L-proline and L-serine and Kreb cycle intermediates as a primary carbon and energy source [113]. Mutants of the L-serine dehydratase gene $s d a A$ were defective to catabolize L-serine and their colonization potential in chicks was abolished [114]. Moreover, sdaA was upregulated more than two-fold in $C$. jejuni upon colonizing the chick cecum, indicating the importance of serine for in vivo survival [26]. Also aspA has been demonstrated to be upregulated (by 4.8 -fold) in the chick cecum [115]. An aspA mutant, which was unable to use any amino acid besides L-serine, was shown to have impaired ability to persist in the intestines of outbred chickens, which can possibly be explained by the reduced growth potential of this mutant in the avian gut, because aspartate enhances oxygen-limited growth of $C$. jejuni in an AspA-dependent way. Also mutation in one of two genes probably involved in amino acid transportation in C. jejuni, livJ and cj0903c, resulted in a marked colonization defect in chicks [32].

Due to an observed reduction in adhesion to and invasion in cultured epithelial cells the PEB1a protein has been regarded as a putative adhesin $[77,116]$. A peb1A mutant was not capable of colonizing chicks but did, however, not show a reduced binding capacity to chicken LMH cells [77]. This suggests that PEB1a serves a role other than, or next to, mediating adhesion during in vivo colonization. Indeed, the protein is mainly located in the periplasm and is believed to function as an $A B C$ transporter of aspartate and glutamate, essential for the utilization of these amino acids as a carbon source during microaerobic growth $[77,102,116]$. However, the twocomponent signal peptide of PEB1a might be responsible for its localization both in the periplasm as on the cell surface, where it could act as an adhesin [116]. It is unclear whether PEB1a is present in the outer membrane, but it can definitely be found in the supernatant of C. jejuni cultures, indicating that the protein can be exported across the outer membrane. Nevertheless, no direct evidence is available that PEB1a functions as an adhesin in C. jejuni. Therefore, the inability of the peb1A mutant to colonize chicks [77] is probably attributable to the inability of this mutant to utilize glutathione, glutamine and the dipeptide $\gamma$-glutamylcysteine, although GGT activity is not affected. Thus, GGT allows the utilization of these nutrients by generating glutamate, which is then taken up by the PEB1a-dependent transporter and subsequently used as a carbon source [100].

To conclude, due to its assaccharolytic and microaerobic nature, $C$. jejuni is dependent on amino acids and electron acceptors other than oxygen as primary energy sources for optimal growth. Although the underlying mechanisms are not yet fully characterized, several of the key molecules and genes of the central intermediary and energy metabolism have been identified to date. It is clear that disturbance in the proper metabolism of these nutrients is accompanied by a severely hampered survival potential and colonization ability in chicks.

\section{Vaccine Application Versus Immune Evasion}

Although generally accepted that $C$. jejuni colonizes its avian host as a commensal, $C$. jejuni inefficiently adheres to and invades cells of the chicken gut epithelium [117]. This is initially followed by an inefficient inate immune response by the chick resulting eventually in the production of specific antibodies $[117,118]$. Although such a response is not able to clear C. jejuni from the gut, reduced bacterial counts have been observed [118]. Moreover, if antibodies against $C$. jejuni are already present in the chick the ability of $C$. jejuni to colonize is dramatically reduced, be it due to transfer of maternal antibodies to or through immunization of such birds $[13,118]$. Therefore, the recent identification of many of the factors needed by $C$. jejuni to colonize the chicken gut opens the way for subunit vaccine development to eradicate this pathogen from poultry flocks.

Potential vaccine candidates must be expressed during and being important for colonization in chicks. In addition they should ideally be highly immunogenic, conserved and prevalent among $C$. jejuni isolates. Although some promising results were obtained focussing on $C$. jejuni outer membrane proteins (OmpH1 and Omp18) and FlaA as subunit vaccine candidates, no effective commercial vaccine against Campylobacter in chicks is available to date [6].

Bacterial OMPs are regarded as promising vaccine components because of their accessibility for the host immune system and the key roles they play in the host-bacterium cross-talk [119]. CadF and CfrA may therefore hold much promise for such applications. Not only are they highly conserved and prevalent in C. jejuni strains, but these surface-exposed proteins are also highly immunogenic in chicks $[118,119]$. Moreover, antibodies directed to CfrA were recently suggested to hinder the interaction of FeEnt with this receptor [91,119]. C. jejuni periplasmic PEB1 can 
possibly be transported across the outer membrane and is highly immunogenic in humans. Whether this immunogenicity can be extended to the chicken host is not known, but clearly PEB1 deserves further attention as a possible candidate for vaccination studies in chicks. Finally, Cj0178, the secreted $\mathrm{CiaB}$ and transmembrane Tlp-10 may be immunogenic but their precise role during chick colonization has yet to be determined.

Also C. jejuni surface-exposed polysaccharide structures may be promising candidates for subunit vaccines. Indeed, several genes essential for successful colonization ( $k p s M$, flaA, flgK, pglH, maf5 and cj1324) are involved in SACS biosynthesis. However, most SACS are highly variable and implicated in immune evasion in humans. Whether this can be extended to the chicken host is not clear. In any case, identification of conserved polysachharide epitopes of SACS is critical for exploiting these structures for vaccine application.

Finally, a plethora of other $C$. jejuni factors are indispensable for chicken gut colonization. These include $z n u A$, cj0379, docA, docB, perR, fur, ceuE, katA, dnaJ and sodB, as well as the (highly) conserved $c j 0415$, tatC and $p p k 1$ genes. Their gene products are, however, not known to be surface-expressed, but rather reside in the peri- or cytoplasm where they exert their vital roles. As a consequence, they do not come in direct contact with the chick immune system. Nevertheless, their identification significantly contributes to a better understanding in the C. jejuni biology during chick colonization. Therefore, it could be useful to examine whether (and how) also these targets could be exploited for $C$. jejuni control in poultry.

\section{Concluding Remarks}

Poultry is a natural host for zoonotic Campylobacter species and the broiler chicken gut is often colonized by C. jejuni in particular. As a result, chicken meat products are considered to be the main source of campylobacteriosis in humans. Despite many efforts, no effective strategy exists to clear this pathogen from chickens, in part due to the poor understanding of their dual interaction. Besides genes which are probably necessary during colonization of the GI tract in a wide range of animal species in general, it seems that $C$. jejuni needs a distinct set of gene products for optimal adaptation to the unique aspects of the chicken intestinal environment, resulting in high-level cecal colonization. And although information about genes important for C. jejuni colonization in chicks is increasing and some cooperative functional networks (e.g. iron metabolism/oxidative stress defence) crucial for colonization are starting to unravel, the mechanisms by which these factors interplay to form the basis behind the complex interaction of $C$. jejuni with its avian host remain largely unclear. Nevertheless, we can now conclude that several factors and processes, involved in all branches and stages of the $C$. jejuni cellular response, are crucial for the adaptation of this bacterium to the chicken gut and thus indispensable for the organism to colonize its avian host. Some of these critical colonization determinants may be exploited by researchers in the field to develop new, effective vaccines to eradicate this zoonotic pathogen from poultry flocks. Especially CadF, CfrA, Tlp-10, CiaB and PEB1 seem promising targets and further research, including identification of their functional and conserved epitopes, could result in the identification of factors capable of targeting a wide range of the circulating $C$. jejuni strains in poultry.

In conclusion, intensive research in the last few years resulted in the identification of several of the chicken colonization determinants of $C$. jejuni. Further research must give a better insight of how these factors interplay, forming the functional network that is responsible for the highly adapted nature of this organism to the avian gut. Unravelling these mechanisms might aid in the development of more efficient control measures for clearing this zoonotic pathogen from poultry lines, thereby reducing the number of human campylobacteriosis cases associated with consumption and handling of contaminated poultry meat products.

\section{Acknowledgements}

In the authors' research groups, research on Campylobacter is financially supported by the Federal Public Service of Health, Food Chain Safety and Environment (FOD, Brussels, Belgium): project RT08/8-CAMPOUL.

\section{Author details}

'Department of Pathology, Bacteriology and Avian Diseases, Faculty of Veterinary Medicine, Ghent University, Salisburylaan 133, 9820 Merelbeke, Belgium. ${ }^{2}$ Institute for Agricultural and Fisheries Research, Technology and Food Unit, Brusselsesteenweg 370, 9090 Melle, Belgium. ${ }^{3}$ Current address: Biological Hazards (BIOHAZ) Unit, European Food Safety Authority (EFSA), Largo N. Palli 5/A, I-43121 Parma, Italy.

\section{Authors' contributions}

$\mathrm{DH}$ drafted the manuscript. KVD and FP helped to draft the manuscript. AM, $\mathrm{FVI}, \mathrm{WM}, \mathrm{MH}$ and $\mathrm{FH}$ were involved in revising the manuscript critically for important intellectual content. All authors read and approved the final manuscript.

\section{Authors' information}

The views and findings in this article are solely those of Dr Winy Messens and do not necessarily reflect the views or position of the European Food Safety Authority.

\section{Competing interests}

The authors declare that they have no competing interests.

Received: 3 March 2011 Accepted: 29 June 2011

Published: 29 June 2011

\section{References}

1. Ailes E, Demma L, Hurd S, Hatch J, Jones TF, Vugia D, Cronquist A, TobinD'Angelo M, Larson K, Laine E, Edge K, Zansky S, Scallan E: Continued decline in the incidence of Campylobacter infections, FoodNet 19962006. Foodborne Pathog Dis 2008, 5:329-337.

2. EFSA: The community summary report on trends and sources of zoonoses, zoonotic agents and food-borne outbreaks in the European Union in 2008. EFSA J 2010, 1496. 
3. Berrang ME, Buhr RJ, Cason JA, Dickens JA: Broiler carcass contamination with Campylobacter from feces during defeathering. J Food Prot 2001, 64:2063-2066

4. EFSA, Panel on Biological Hazards (BIOHAZ): Scientific opinion on quantification of the risk posed by broiler meat to human campylobacteriosis in the EU. EFSA J 2010, 8:1437.

5. Rosenquist H, Sommer HM, Nielsen NL, Christensen BB: The effect of slaughter operations on the contamination of chicken carcasses with thermotolerant Campylobacter. Int J Food Microbiol 2006, 108:226-232.

6. Hermans D, Van Deun K, Messens W, Martel A, Van Immerseel F, Haesebrouck F, Rasschaert G, Heyndrickx M, Pasmans F: Campylobacter control in poultry by current intervention measures ineffective: urgent need for intensified fundamental research. Vet Microbiol 2011

7. Beery JT, Hugdahl MB, Doyle MP: Colonization of gastrointestinal tracts of chicks by Campylobacter jejuni. Appl Environ Microbiol 1988, 54:2365-2370

8. Meade KG, Nirciandi F, Cahalane S, Reiman C, Allan B, O'Farrelly C: Comparative in vivo infection models yield insights on early host immune response to Campylobacter in chickens. Immunogenetics 2009. 61:101-110.

9. Stern NJ, Bailey JS, Blankenship LC, Cox NA, McHan F: Colonization characteristics of Campylobacter jejuni in chick ceca. Avian Dis 1988, 32:330-334.

10. Coward C, van Diemen PM, Conlan AJK, Gog JR, Stevens MP, Jones MA, Maskell DJ: Competing isogenic Campylobacter strains exhibit variable population structures in vivo. Appl Environ Microbiol 2008, 74:3857-3867.

11. Jacobs-Reitsma WF, van de Giessen AW, Bolder NM, Mulder RW Epidemiology of Campylobacter spp. at two Dutch broiler farms. Epidemiol Infect 1995, 114:413-421.

12. van Gerwe T, Miflin JK, Templeton JM, Bouma A, Wagenaar JA, JacobsReitsma WF, Stegeman A, Klinkenberg D: Quantifying transmission of Campylobacter jejuni in commercial broiler flocks. Appl Environ Microbiol 2009, 75:625-628.

13. Sahin O, Luo N, Huang S, Zhang Q: Effect of Campylobacter-specific maternal antibodies on Campylobacter jejuni colonization in young chickens. Appl Environ Microbiol 2003, 69:5372-5379.

14. Stern NJ, Cox NA, Musgrove MT, Park CM: Incidence and levels of Campylobacter in broilers after exposure to an inoculated seeder bird. J Appl Poult Res 2001, 10:315-318.

15. Stern NJ: Salmonella species and Campylobacter jejuni cecal colonization model in broilers. Poult Sci 2008, 87:2399-2403.

16. Hanel I, Borrmann E, Muller J, Muller W, Pauly B, Liebler-Tenorio EM, Schulze F: Genomic and phenotypic changes of Campylobacter jejuni strains after passage of the chicken gut. Vet Microbiol 2009, 136:121-129.

17. Ringoir DD, Korolik V: Colonisation phenotype and colonisation potential differences in Campylobacter jejuni strains in chickens before and after passage in vivo. Vet Microbiol 2003, 92:225-235.

18. Korolik V, Alderton MR, Smith SC, Chang J, Coloe PJ: Isolation and molecular analysis of colonising and non-colonising strains of Campylobacter jejuni and Campylobacter coli following experimental infection of young chickens. Vet Microbiol 1998, 60:239-249.

19. Sang FC, Shane SM, Yogasundram K, Hagstad HV, Kearney MT: Enhancement of Campylobacter jejuni virulence by serial passage in chicks. Avian Dis 1989, 33:425-430.

20. Cawthraw SA, Wassenaar TM, Ayling R, Newell DG: Increased colonization potential of Campylobacter jejuni strain 81116 after passage through chickens and its implication on the rate of transmission within flocks. Epidemiol Infect 1996, 117:213-215.

21. Murphy C, Carroll C, Jordan KN: Environmental survival mechanisms of the foodborne pathogen Campylobacter jejuni. J Appl Microbiol 2006, 100:623-632.

22. Newell DG: The ecology of Campylobacter jejuni in avian and human hosts and in the environment. Int J Infect Dis 2002, 6:3S16-3S21.

23. Lin J, Michel LO, Zhang QJ: CmeABC functions as a multidrug efflux system in Campylobacter jejuni. Antimicrob Agents Chemother 2002, 46:2124-2131.

24. Lin J, Sahin O, Michel LO, Zhang Q: Critical role of multidrug efflux pump CmeABC in bile resistance and in vivo colonization of Campylobacter jejuni. Infect Immun 2003, 71:4250-4259.

25. Guo BQ, Wang Y, Shi F, Barton Y-W, Plummer P, Reynolds DL, Nettleton D, Grinnage-Pulley T, Lin J, Zhang Q: CmeR functions as a pleiotropic regulator and is required for optimal colonization of Campylobacter jejuni in vivo. J Bacteriol 2008, 190:1879-1890.

26. Woodall CA, Jones MA, Barrow PA, Hinds J, Marsden GL, Kelly DJ, Dorrell N, Wren BW, Maskell DJ: Campylobacter jejuni gene expression in the chick cecum: evidence for adaptation to a low-oxygen environment. Infect Immun 2005, 73:5278-5285

27. Raphael BH, Pereira S, Flom GA, Zhang Q, Ketley JM, Konkel ME: The Campylobacter jejuni response regulator, $\mathrm{CbrR}$, modulates sodium deoxycholate resistance and chicken colonization. J Bacteriol 2005, 187:3662-3670

28. Stephens BB, Loar SN, Alexandre G: Role of CheB and CheR in the complex chemotactic and aerotactic pathway of Azospirillum brasilense. J Bacteriol 2006, 188:4759-4768.

29. Kanungpean D, Kakuda T, Takai S: Participation of CheR and CheB in chemosensory response of Campylobacter jejuni. Microbiology 2011, 157:1279-1289.

30. Hugdahl MB, Beery JT, Doyle MP: Chemotactic behavior of Campylobacter jejuni. Infect Immun 1988, 56:1560-1566.

31. Vegge $C S$, Brondsted L, Li YP, Bang DD, Ingmer H: Energy taxis drives Campylobacter jejuni toward the most favorable conditions for growth Appl Environ Microbiol 2009, 75:5308-5314.

32. Hendrixson DR, DiRita VJ: Identification of Campylobacter jejuni genes involved in commensal colonization of the chick gastrointestinal tract. Mol Microbiol 2004, 52:471-484

33. Hartley-Tassell LE, Shewell LK, Day CJ, Wilson JC, Sandhu R, Ketley JM, Korolik V: Identification and characterization of the aspartate chemosensory receptor of Campylobacter jejuni. Mol Microbiol 2010, 75:710-730.

34. Golden NJ, Acheson DW: Identification of motility and autoagglutination Campylobacter jejuni mutants by random transposon mutagenesis. Infect Immun 2002, 70:1761-1771.

35. Quinones B, Miller WG, Bates AH, Mandrell RE: Autoinducer-2 production in Campylobacter jejuni contributes to chicken colonization. Appl Environ Microbiol 2009, 75:281-285

36. Nachamkin I, Yang XH, Stern NJ: Role of Campylobacter jejuni flagella as colonization factors for 3-day-old chicks - analysis with flagellar mutants. Appl Environ Microbiol 1993, 59:1269-1273.

37. Hendrixson DR, Akerley BJ, DiRita VJ: Transposon mutagenesis of Campylobacter jejuni identifies a bipartite energy taxis system required for motility. Mol Microbiol 2001, 40:214-224.

38. Nuijten PJ, van Asten FJ, Gaastra W, van der Zeijst BA: Structural and functional analysis of two Campylobacter jejuni flagellin genes. J Biol Chem 1990, 265:17798-17804

39. Alm RA, Guerry P, Trust TJ: The Campylobacter $\sigma^{54}$ flaB flagellin promoter is subject to environmental regulation. J Bacterio/ 1993, 175:4448-4455.

40. Allen KJ Griffiths MW: Effect of environmental and chemotactic stimuli on the activity of the Campylobacter jejuni flaA $\sigma^{28}$ promoter. FEMS Microbiol Lett 2001, 205:43-48

41. Ding $W$, Wang $H$, Griffiths MW: Probiotics down-regulate flaA $\sigma^{28}$ promoter in Campylobacter jejuni. J Food Prot 2005, 68:2295-2300.

42. Guerry P, Logan SM, Thornton S, Trust TJ: Genomic organization and expression of Campylobacter flagellin genes. J Bacteriol 1990, 172:1853-1860.

43. Wosten MM, Wagenaar JA, van Putten JP: The FlgS/FlgR two-component signal transduction system regulates the fla regulon in Campylobacter jejuni. J Biol Chem 2004, 279:16214-16222.

44. Jones MA, Marston KL, Woodall CA, Maskell DJ, Linton D, Karlyshev AV, Dorrell N, Wren BW, Barrow PA: Adaptation of Campylobacter jejuni NCTC11168 to high-level colonization of the avian gastrointestinal tract. Infect Immun 2004, 72:3769-3776.

45. Wassenaar TM, van der Zeijst BA, Ayling R, Newell DG: Colonization of chicks by motility mutants of Campylobacter jejuni demonstrates the importance of flagellin A expression. J Gen Microbiol 1993, 139:1171-1175.

46. Neal-McKinney JM, Christensen JE, Konkel ME: Amino-terminal residues dictate the export efficiency of the Campylobacter jejuni filament proteins via the flagellum. Mol Microbiol 2010, 76:918-931.

47. Karlyshev AV, Linton D, Gregson NA, Wren BW: A novel paralogous gene family involved in phase-variable flagella-mediated motility in Campylobacter jejuni. Microbiology 2002, 148:473-480.

48. Fernando U, Biswas D, Allan B, Willson P, Potter AA: Influence of Campylobacter jejuni fliA, rpoN and flgK genes on colonization of the chicken gut. Int J Food Microbiol 2007, 118:194-200. 
49. Hiett KL, Stintzi A, Andacht TM, Kuntz RL, Seal BS: Genomic differences between Campylobacter jejuni isolates identify surface membrane and flagellar function gene products potentially important for colonizing the chicken intestine. Funct Integr Genomics 2008, 8:407-420.

50. Karlyshev AV, Ketley JM, Wren BW: The Campylobacter jejuni glycome. FEMS Microbiol Rev 2005, 29:377-390.

51. Champion OL, Gaunt MW, Gundogdu O, Elmi A, Witney AA, Hinds J, Dorrell N, Wren BW: Comparative phylogenomics of the food-borne pathogen Campylobacter jejuni reveals genetic markers predictive of infection source. Proc Natl Acad Sci USA 2005, 102:16043-16048.

52. Howard SL, Jagannathan A, Soo EC, Hui JPM, Aubry AJ, Ahmed I, Karlyshev A, Kelly JF, Jones MA, Stevens MP, Logan SM, Wren BW Campylobacter jejuni glycosylation island important in cell charge, legionaminic acid biosynthesis, and colonization of chickens. Infect Immun 2009, 77:2544-2556

53. Konkel ME, Klena JD, Rivera-Amill V, Monteville MR, Biswas D, Raphael B, Mickelson J: Secretion of virulence proteins from Campylobacter jejuni is dependent on a functional flagellar export apparatus. J Bacterio/ 2004 186:3296-3303.

54. Konkel ME, Kim BJ, Rivera-Amill V, Garvis SG: Bacterial secreted proteins are required for the internalization of Campylobacter jejuni into cultured mammalian cells. Mol Microbiol 1999, 32:691-701.

55. Ziprin RL, Young CR, Byrd JA, Stanker LH, Hume ME, Gray SA, Kim BJ, Konkel ME: Role of Campylobacter jejuni potential virulence genes in cecal colonization. Avian Dis 2001, 45:549-557.

56. Biswas D, Fernando UM, Reiman CD, Willson PJ, Townsend HGG, Potter AA, Allan BJ: Correlation between in vitro secretion of virulence-associated proteins of Campylobacter jejuni and colonization of chickens. Curr Microbiol 2007, 54:207-212.

57. Karlyshev AV, Linton D, Gregson NA, Lastovica AJ, Wren BW: Genetic and biochemical evidence of a Campylobacter jejuni capsular polysaccharide that accounts for Penner serotype specificity. Mol Microbiol 2000, 35:529-541.

58. Louwen R, Heikema A, van Belkum A, Ott A, Gilbert M, Ang W, Endtz HP, Bergman MP, Nieuwenhuis EE: The sialylated lipooligosaccharide outer core in Campylobacter jejuni is an important determinant for epithelial cell invasion. Infect Immun 2008, 76:4431-4438.

59. Guerry P, Ewing CP, Hickey TE, Prendergast MM, Moran AP: Sialylation of lipooligosaccharide core affects immunogenicity and serum resistance of Campylobacter jejuni. Infect Immun 2000, 68:6656-6662.

60. Habib I, Louwen R, Uyttendaele M, Houf K, Vandenberg O, Nieuwenhuis EE, Miller WG, van Belkum A, De Zutter L: Correlation between genotypic diversity, lipooligosaccharide gene locus class variation and Caco-2 cell invasion potential of Campylobacter jejuni isolates from chicken meat and humans: contribution to virulotyping. App/ Environ Microbiol 2009, 75:4277-4288.

61. Roberts IS: The biochemistry and genetics of capsular polysaccharide production in bacteria. Annu Rev Microbiol 1996, 50:285-315.

62. Bacon DJ, Szymanski CM, Burr DH, Silver RP, Alm RA, Guerry P: A phasevariable capsule is involved in virulence of Campylobacter jejuni 81-176. Mol Microbiol 2001, 40:769-777.

63. Bachtiar BM, Coloe PJ, Fry BN: Knockout mutagenesis of the kpsE gene of Campylobacter jejuni 81116 and its involvement in bacterium-host interactions. FEMS Immunol Med Microbiol 2007, 49:149-154.

64. Parkhill J, Wren BW, Mungall K, Ketley JM, Churcher C, Basham D, Chillingworth T, Davies RM, Feltwell T, Holroyd S, Jagels K, Karlyshev AV, Moule S, Pallen MJ, Penn CW, Quail MA, Rajandream MA, Rutherford KM, van Vliet AHM, Whitehead S, Barrell BG: The genome sequence of the food-borne pathogen Campylobacter jejuni reveals hypervariable sequences. Nature 2000, 403:665-668.

65. Young KT, Davis LM, Dirita VJ: Campylobacter jejuni: molecular biology and pathogenesis. Nat Rev Microbiol 2007, 5:665-679.

66. Kakuda T, DiRita VJ: Cj1496c encodes a Campylobacter jejuni glycoprotein that influences invasion of human epithelial cells and colonization of the chick gastrointestinal tract. Infect Immun 2006, 74:4715-4723.

67. Szymanski CM, Yao R, Ewing CP, Trust TJ, Guerry P: Evidence for a system of general protein glycoslylation in Campylobacter jejuni. Mol Microbiol 1999, 32:1022-1030.

68. Karlyshev AV, Everest P, Linton D, Cawthraw S, Newell DG, Wren BW: The Campylobacter jejuni general glycosylation system is important for attachment to human epithelial cells and in the colonization of chicks. Microbiology 2004, 150:1957-1964.

69. Young NM, Brisson JR, Kelly J, Watson DC, Tessier L, Lanthier PH, Jarrell HC, Cadotte N, St Michael F, Aberg E, Szymanski CM: Structure of the N-linked glycan present on multiple glycoproteins in the Gram-negative bacterium, Campylobacter jejuni. J Biol Chem 2002, 277:42530-42539.

70. Mikkelsen $\mathrm{H}$, Sivaneson M, Filloux A: Key two-component regulatory systems that control biofilm formation in Pseudomonas aeruginosa. Environm Microbiol 2011.

71. Bras AM, Chatterjee S, Wren BW, Newell DG, Ketley JM: A novel Campylobacter jejuni two-component regulatory system important for temperature-dependent growth and colonization. J Bacteriol 1999, 181:3298-3302

72. MacKichan JK, Gaynor EC, Chang C, Cawthraw S, Newell DG, Miller JF, Falkow S: The Campylobacter jejuni dccRS two-component system is required for optimal in vivo colonization but is dispensable for in vitro growth. Mol Microbiol 2004, 54:1269-1286.

73. Svensson SL, Davis LM, MacKichan JK, Allan BJ, Pajaniappan M, Thompson SA, Gaynor EC: The CprS sensor kinase of the zoonotic pathogen Campylobacter jejuni influences biofilm formation and is required for optimal chick colonization. Mol Microbiol 2009, 71:253-272.

74. Zhang MJ, Xiao D, Zhao F, Gu YX, Meng FL, He LH, Ma GY, Zhang JZ: Comparative proteomic analysis of Campylobacter jejuni cultured at $37^{\circ} \mathrm{C}$ and $42^{\circ} \mathrm{C}$. Jpn J Infect Dis 2009, 62:356-361.

75. Konkel ME, Kim BJ, Klena JD, Young CR, Ziprin R: Characterization of the thermal stress response of Campylobacter jejuni. Infect Immun 1998, 66:3666-3672

76. Ashgar SS, Oldfield NJ, Wooldridge KG, Jones MA, Irving GJ, Turner DP, Ala'Aldeen DA: CapA, an autotransporter protein of Campylobacter jejuni mediates association with human epithelial cells and colonization of the chicken gut. J Bacteriol 2007, 189:1856-1865.

77. Flanagan RC, Neal-McKinney JM, Dhillon AS, Miller WG, Konkel ME: Examination of Campylobacter jejuni putative adhesins leads to the identification of a new protein, designated FlpA, required for chicken colonization. Infect Immun 2009, 77:2399-2407

78. Friis C, Wassenaar TM, Javed MA, Snipen L, Lagesen K, Hallin PF, Newell DG, Toszeghy M, Ridley A, Manning G, Ussery DW: Genomic characterization of Campylobacter jejuni strain M1. PLoS One 2010, 5:e12253.

79. Konkel ME, Garvis SG, Tipton SL, Anderson DE Jr, Cieplak W Jr: Identification and molecular cloning of a gene encoding a fibronectinbinding protein, (CadF), from Campylobacter jejuni. Mol Microbiol 1997, 24:953-963.

80. Ziprin RL, Young CR, Stanker LH, Hume ME, Konkel ME: The absence of cecal colonization of chicks by a mutant of Campylobacter jejuni not expressing bacterial fibronectin-binding protein. Avian Dis 1999, 43:586-589.

81. Rizal A, Kumar A, Vidyarthi AS: Prevalence of pathogenic genes in Campylobacter jejuni isolates from poultry and human. Internet J Food Safety 2010, 12:29-34.

82. Dekker N: Outer-membrane phospholipase A: known structure, unknown biological function. Mol Microbiol 2000, 35:711-717.

83. Konkel ME, Christensen JE, Dhillon AS, Lane AB, Hare-Sanford R, Schaberg DM, Larson CL: Campylobacter jejuni strains compete for colonization in broiler chicks. Appl Environ Microbiol 2007, 73:2297-2305.

84. Van Deun K, Pasmans F, Ducatelle R, Flahou B, Vissenberg K, Martel A, Vanden Broeck W, Van Immerseel F, Haesebrouck F: Colonization strategy of Campylobacter jejuni results in persistent infection of the chicken gut. Vet Microbiol 2008, 130:285-297.

85. Byrne CM, Clyne M, Bourke B: Campylobacter jejuni adhere to and invade chicken intestinal epithelial cells in vitro. Microbiology 2007, 153:561-569.

86. Hu L, Kopecko DJ: Campylobacter jejuni 81-176 associates with microtubules and dynein during invasion of human intestinal cells. Infect Immun 1999, 67:4171-4182.

87. Watson RO, Galan JE: Campylobacter jejuni survives within epithelial cells by avoiding delivery to lysosomes. PLOS Pathog 2008, 4:e14.

88. Palyada K, Threadgill D, Stintzi A: Iron acquisition and regulation in Campylobacter jejuni. J Bacterio/ 2004, 186:4714-4729.

89. Naikare H, Palyada K, Panciera R, Marlow D, Stintzi A: Major role for FeoB in Campylobacter jejuni ferrous iron acquisition, gut colonization, and intracellular survival. Infect Immun 2006, 74:5433-5444. 
90. Xu F, Zeng X, Haigh RD, Ketley JM, Lin J: Identification and characterization of a new ferric enterobactin receptor, $\mathrm{CfrB}$, in Campylobacter. J Bacteriol 2010, 192:4425-4435.

91. Davis LM, Kakuda T, DiRita VJ: A Campylobacter jejuni znuA orthologue is essential for growth in low-zinc environments and chick colonization. J Bacteriol 2009, 191:1631-1640.

92. Atack JM, Kelly DJ: Oxidative stress in Campylobacter jejuni: responses, resistance and regulation. Future Microbiol 2009, 4:677-690.

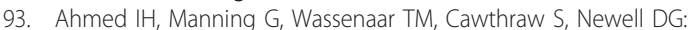
Identification of genetic differences between two Campylobacter jejuni strains with different colonization potentials. Microbiology 2002, 148:1203-1212.

94. Bingham-Ramos LK, Hendrixson DR: Characterization of two putative cytochrome c peroxidases of Campylobacter jejuni involved in promoting commensal colonization of poultry. Infect Immun 2008, 76:1105-1114.

95. Palyada K, Sun YQ, Flint A, Butcher J, Naikare H, Stintzi A: Characterization of the oxidative stress stimulon and PerR regulon of Campylobacter jejuni. BMC Genomics 2009, 10:481.

96. Garenaux A, Guillou S, Ermel G, Wren B, Federighi M, Ritz M: Role of the Cj1371 periplasmic protein and the Cj0355c two-component regulator in the Campylobacter jejuni NCTC 11168 response to oxidative stress caused by paraquat. Res Microbiol 2008, 159:718-726.

97. O'Donovan DJ, Fernandes CJ: Mitochondrial glutathione and oxidative stress: implications for pulmonary oxygen toxicity in premature infants. Mol Genet Metab 2000, 71:352-358.

98. Tate SS, Meister A: Gamma-glutamyl transpeptidase: catalytic, structural and functional aspects. Mol Cell Biochem 1981, 39:357-368.

99. Barnes HA, Bagnall MC, Browning DD, Thompson SA, Manning G, Newell DG: Gamma-glutamyl transpeptidase has a role in the persistent colonization of the avian gut by Campylobacter jejuni. Microb Pathog 2007, 43:198-207.

100. Hofreuter D, Novik V, Galan JE: Metabolic diversity in Campylobacter jejuni enhances specific tissue colonization. Cell Host Microbe 2008, 4:425-433.

101. Candon HL, Allan BJ, Fraley CD, Gaynor EC: Polyphosphate kinase 1 is a pathogenesis determinant in Campylobacter jejuni. J Bacteriol 2007, 189:8099-8108.

102. Gangaiah D, Liu Z, Arcos J, Kassem II, Sanad Y, Torelles JB, Rajashekara G: Polyphosphate kinase 2: a novel determinant of stress responses and pathogenesis in Campylobacter jejuni. PLoS One 2010, 5:e12142.

103. Shepherd M, Bernhardt PV, Poole RK: Globin-mediated nitric oxide detoxification in the foodborne pathogenic bacterium Campylobacter jejuni proceeds via a dioxygenase or denitrosylase mechanism. Nitric Oxide 2011.

104. Pittman MS, Kelly DJ: Electron transport through nitrate and nitrite reductases in Campylobacter jejuni. Biochem Soc Trans 2005, 33:190-192.

105. Smith H, Shepherd M, Monk C, Green J, Poole RK: The NO-responsive hemoglobins of Campylobacter jejuni: concerted responses of two globins to $\mathrm{NO}$ and evidence in vitro for globin regulation by the transcription factor NssR. Nitric Oxide 2011, 73:2094-2100.

106. Elvers KT, Turner SM, Wainwright LM, Marsden G, Hinds J, Cole JA, Poole RK, Penn CW, Park SF: NssR, a member of the Crp-Fnr superfamiliy from Campylobacter jejuni, regulates a nitrosative stress-response regulon that includes both a single-domain and a truncated haemoglobin. $\mathrm{Mol}$ Microbiol 2005, 57:735-750.

107. Hitchcock A, Hall SJ, Myers JD, Mulholland F, Jones MA, Kelly DJ: Roles of the twin arginine translocase and associated chaperones in the biogenesis of the electron transport chains of the human pathogen Campylobacter jejuni. Microbiology 2010, 156:2994-3010.

108. Rajashekara G, Drozd M, Gangaiah D, Jeon B, Liu Z, Zhang QJ: Functional characterization of the twin-arginine translocation system in Campylobacter jejuni. Foodborne Pathog Dis 2009, 6:935-945.

109. Weingarten RA, Taveirne ME, Olson JW: The dual-functioning fumarate reductase is the sole succinate:quinone reductase in Campylobacter jejuni and is required for full host colonization. J Bacteriol 2009, 191:5293-5300.

110. Weerakoon DR, Borden NJ, Goodson CM, Grimes J, Olson JW: The role of respiratory donor enzymes in Campylobacter jejuni host colonization and physiology. Microb Pathog 2009, 47:8-15.
111. Weingarten RA, Grimes JL, Olson JW: Role of Campylobacter jejuni respiratory oxidases and reductases in host colonization. Appl Environ Microbiol 2008, 74:1367-1375.

112. Pajaniappan M, Hall JE, Cawthraw SA, Newell DG, Gaynor EC, Fields JA, Rathbun KM, Agee WA, Burns CM, Hall SJ, Kelly DJ, Thompson SA: A temperature-regulated Campylobacter jejuni gluconate dehydrogenase is involved in respiration-dependent energy conservation and chicken colonization. Mol Microbiol 2008, 68:474-491.

113. Kelly DJ: Campylobacter.Edited by: Szymanski CM, Nachamkin I, Blaser MJ. ASM Press, Herndon, VA; , third 2008:41-61.

114. Velayudhan J, Jones MA, Barrow PA, Kelly DJ: L-serine catabolism via an oxygen-labile L-serine dehydratase is essential for colonization of the avian gut by Campylobacter jejuni. Infect Immun 2004, 72:260-268.

115. Guccione E, Leon-Kempis MD, Pearson BM, Hitchin E, Mulholland F, van Diemen PM, Stevens MP, Kelly DJ: Amino acid-dependent growth of Campylobacter jejuni: key roles for aspartase (AspA), under microaerobic and oxygen-limited conditions and identification of AspB (Cj0762), essential for growth on glutamate. Mol Microbiol 2008, 69:77-93.

116. Leon-Kempis MD, Guccione E, Mulholland F, Williamson MP, Kelly DJ: The Campylobacter jejuni PEB1a adhesin is an aspartate/glutamate-binding protein of an $A B C$ transporter essential for microaerobic growth on dicarboxylic amino acids. Mol Microbiol 2006, 60:1262-1275.

117. Larson CL, Shah DH, Dhillon AS, Call DR, Ahn S, Haldorson GJ, Davitt C, Konkel ME: Campylobacter jejuni invade chicken LMH cells inefficiently and stimulate differential expression of the chicken CXCLi1 and CXCLi2 cytokines. Microbiology 2008, 154:3835-3847.

118. Shoaf-Sweeney KD, Larson CL, Tang X, Konkel ME: Identification of Campylobacter jejuni proteins recognized by maternal antibodies of chickens. Appl Environ Microbiol 2008, 74:6867-6875.

119. Zeng $X, X u F$, Lin J: Molecular, antigenic and functional characteristics of ferric enterobactin receptor CfrA in Campylobacter jejuni. Infect Immun 2009, 77:5437-5448.

doi:10.1186/1297-9716-42-82

Cite this article as: Hermans et al:: Colonization factors of Campylobacter jejuni in the chicken gut. Veterinary Research 2011 42:82.

\section{Submit your next manuscript to BioMed Central and take full advantage of:}

- Convenient online submission

- Thorough peer review

- No space constraints or color figure charges

- Immediate publication on acceptance

- Inclusion in PubMed, CAS, Scopus and Google Scholar

- Research which is freely available for redistribution

Submit your manuscript at www.biomedcentral.com/submit
C Biomed Central 